\title{
Trajetórias de local de moradia, estudo e trabalho dos jovens brasileiros entre 2003 e 2011: uma análise de entropia
}

\author{
Thiago Dumont Oliveira* \\ André Braz Golgher ${ }^{\star *}$ \\ Pedro Mendes Loureiro ${ }^{\star \star *}$
}

\begin{abstract}
Diversos estudos mostram que, em vários países, incluindo o Brasil, o período em que os jovens permanecem na casa dos pais aumentou constantemente entre 1970 e 2000.0 presente trabalho analisa a decisão dos jovens de sair da casa dos pais, sair da escola e entrar no mercado de trabalho, com o objetivo de identificar se o bom desempenho da economia brasileira entre 2003 e 2011 promoveu a aceleração dessas transições para a vida adulta. Utilizando os microdados da PNAD, calculou-se a proporção de jovens de 15 a 34 anos de áreas metropolitanas que moram com os pais, que estudam e que trabalham. Em seguida, utiliza-se a análise de entropia com o objetivo de investigar essas três dimensões conjuntamente. Os resultados sugerem uma quebra com o paradigma do prolongamento da juventude amplamente discutido nas últimas décadas: houve uma aceleração da transição para a vida adulta no período analisado.
\end{abstract}

Palavras-chave: Análise de entropia. Arranjo domiciliar. Educação. Mercado de trabalho. Transição para a vida adulta.

\footnotetext{
* Centro de Desenvolvimento e Planejamento Regional (Cedeplar), Universidade Federal de Minas Gerais (UFMG), Belo Horizonte-MG, Brasil (oliveiraeconomia@gmail.com).

** Centro de Desenvolvimento e Planejamento Regional (Cedeplar), Universidade Federal de Minas Gerais (UFMG), Belo Horizonte-MG, Brasil (agolgher@cedeplar.ufmg.br).

${ }^{* \star *}$ School of Oriental and African Studies (Soas), University of London, Londres, Reino Unido (Impedro@gmail.com), bolsista da Capes, bolsa BEX-0840-14-9.
} 


\section{Introdução}

A transição para a vida adulta é um fenômeno mundial amplamente discutido pela literatura. Para Shanahan (2000), essa transição é caracterizada por diversos fatores, como deixar de ser estudante, começar a trabalhar, sair do domicílio de origem, casar e ter filhos. O objetivo desse trabalho é analisar uma importante dimensão deste processo, resumida nos três primeiros fatores apontados, no sentido de verificar se o período entre 2003 e 2011 rompe com a tendência que estes fenômenos descreveram durante as últimas décadas.

Com relação à mudança de estado civil e fecundidade, importantes transformações ocorreram devido a aspectos associados à segunda transição demográfica (SURKYN; LESTHAEGHE, 2004). A idade ao primeiro casamento aumentou, com o adiamento do início da fecundidade, bem como elevaram-se a proporção de casais coabitatando e a procriação em uniões informais. Além disso, a taxa de fecundidade caiu no Brasil e hoje encontra-se abaixo do nível de reposição (POTTER et al., 2010).

Essas mudanças são também muito relevantes na transição do jovem para a vida adulta. No presente trabalho enfatizam-se as transições entre escola e trabalho e entre deixar o domicílio de origem e formar o próprio. Consideramos que discutir conceitos associados ao estado civil e à fecundidade, dada a extensão da bibliografia especializada, implicaria uma análise mais detalhada do que a possível em um artigo. Além disso, o foco em um subgrupo dos processos associados à transição para a vida adulta permite associação mais estreita com fenômenos externos. Entre estes, é de particular relevância o crescimento econômico, que promoveu maior inserção do jovem no mercado de trabalho e, consequentemente, possibilidade de formar o próprio lar.

Entretanto, quais seriam as consequências, para a fecundidade, de um crescimento econômico mais vigoroso? Embora questões financeiras certamente influenciem na decisão de ter filhos, não é claro se essa pode ser considerada a variável mais relevante para tanto. Pode-se argumentar que há múltiplas preferências conflitantes com a fecundidade por parte das mulheres, que podem optar por adiar a parturição e aproveitar as melhores possibilidades oferecidas pelo mercado de trabalho.

A última razão que embasa a escolha dos processos contemplados refere-se ao recorte temporal. Estudar adequadamente a transição para a vida adulta em sua totalidade requereria maior temporalidade (SHANAHAN, 2000), aumentando a heterogeneidade da perspectiva utilizada nessa população investigada e quebrando a associação com um período de crescimento econômico relativamente intenso. Não obstante, nada impede estender a abordagem deste trabalho para incorporar maior número de transições, dada a flexibilidade da metodologia empregada.

Assim, este artigo analisa as trajetórias dos jovens para formar o próprio lar, sair do sistema de ensino e participar do mercado de trabalho, considerando a juventude um período de dependência dos pais. Isto é, o jovem que saiu de casa, mas continua recebendo apoio financeiro dos pais, ainda não completou a transição para a vida adulta segundo esta 
lente; da mesma forma, o jovem que não saiu da casa dos pais, mas já está trabalhando, realizou parcialmente a transição.

A decisão dos filhos de sair de casa ou continuar morando com os pais é influenciada por uma série de fatores de cunhos macroeconômico, microeconômico e sociodemográfico (SHANAHAN, 2000). 0 primeiro conjunto contempla variáveis como taxa de desemprego, salário disponível entre jovens, custo de comprar ou alugar a própria residência, provisão de educação pública pelo governo, grau de dificuldade do jovem em conseguir financiamento para investir em educação, entre outras.

Do ponto de vista microeconômico, a decisão dos filhos de sair de casa ou permanecer no lar é encarada a partir da perspectiva utilitarista. O filho tem demanda por privacidade, mas também por conforto. Portanto, a decisão é pautada em um cálculo no qual dois cenários são comparados quanto aos diferenciais de utilidade. 0 bônus e o ônus de tudo o que está circunscrito à decisão de sair ou não da casa dos pais são contabilizados, as informações são completas e a racionalidade econômica é sempre capaz de resolver a equação. No que se refere aos fatores demográficos, também desempenham papel importante aspectos relacionados à idade, ao sexo, à etnia/cor, à religião, ao estado civil, à escolaridade, à ocupação, à renda, à presença de padrasto/madrasta, à ordem de nascimento, ao local de residência, ao tamanho e composição da família, etc.

Naturalmente, diferenças culturais, institucionais e econômicas entre localidades também afetam a propensão de permanecer ou não na casa dos pais. Por exemplo, em meados da década de 1990, enquanto na Alemanha, França, Reino Unido e Estados Unidos a porcentagem de homens entre 18 e 33 anos morando com os pais variava de $35 \%$ a $45 \%$, na Espanha, Itália, Portugal e Brasil oscilava entre 62\% e 85\% (MANACORDA; MORETTI, 2005; CARVALHO, 2009).

A literatura que trata do prolongamento da juventude, particularmente das relações entre mercado de trabalho e formação do próprio lar, é vasta na Europa e nos Estados Unidos, em contraste com o Brasil. Dificuldades metodológicas apresentam-se em função das diferenças entre as bases de dados brasileiras e as estrangeiras. Esse tema é muito bem abordado com bases longitudinais, ainda raras no Brasil. Assim, o presente trabalho utiliza metodologia pouco explorada nas ciências sociais: a análise de entropia, que permite contornar algumas das limitações impostas pelo uso de dados cross-section. Fussell (2006) foi a pioneira no emprego desse método em estudo sobre os jovens nos Estados Unidos, e Vieira (2008) foi a primeira a usá-lo para abordar o comportamento dos jovens brasileiros.

0 presente artigo discute mudanças de comportamento dos jovens brasileiros no que tange à saída da casa dos pais entre 2003 e 2011. Foge ao escopo do trabalho discutir em que medida essas mudanças são consequência de políticas governamentais; o período escolhido para análise deve-se ao fato de que o país registrou crescimento econômico considerável e ampliação dos postos de trabalho.

Uma vez que a escassez de empregos é uma das variáveis mais importantes para explicar o prolongamento da saída de casa (SHANAHAN, 2000), pode ter havido uma ruptura 
na tendência geral de diminuição do tempo de dependência total ou parcial do jovem com relação aos pais. Ou seja, pretende-se entender como o jovem brasileiro respondeu ao alto crescimento econômico em termos de suas escolhas por formar lar próprio, estudar e trabalhar. Para analisar essas três dimensões de maneira conjunta, foram construídos índices de entropia utilizando os dados da PNAD de 2003 e 2011, seguindo metodologia apresentada por Fussell (2006) e Vieira (2008).

0 artigo está estruturado em sete seções, além dessa introdução. A segunda seção apresenta o conceito de juventude adotado no trabalho. A terceira distingue família e arranjo domiciliar do ponto de vista demográfico. A quarta contém uma revisão da bibliografia referente à formação do próprio domicílio pelo jovem e à transição entre escola e trabalho. A quinta seção especifica dados e métodos, enquanto a sexta discute os resultados e a sétima tece as considerações finais.

\section{Juventude, um fenômeno do século XX}

Apesar do crescente interesse da academia pelo tema, a juventude é um assunto menos estudado no campo da demografia quando comparado a outros fenômenos, como migração, envelhecimento da população e aumento do número de divórcios e de arranjos unipessoais (COBB-CLARK, 2008). Um ponto decisivo para abordar essa questão é a própria definição do termo juventude. De acordo com Mello (2005, p. 21), “juventude poderia ser definida como uma fase de transição entre os limites da dependência e da autonomia. Os jovens aparecem ora tendo pouca idade para algumas coisas, ora já tendo passado da idade para outras coisas". Não obstante, como define Dayrell (2003, p. 42), a “juventude constitui um momento determinado, mas não se reduz a uma passagem, pois os jovens se apresentam como sujeitos sociais, que vivem e se constituem como tais nas relações estabelecidas no seu cotidiano".

De acordo com Carvalho (2009, p. 22): “No início do século XX, a juventude nem sequer possuía uma existência social, pois os indivíduos passavam diretamente da condição de criança para a condição de adulto". A autora argumenta que os padrões sociais predeterminavam as ações dos jovens e, portanto, eles não se tornaram objeto de estudo até a segunda metade do século XX.

Um fator diretamente associado à incorporação do conceito juventude como fase distinta da vida é o adiamento do casamento e da consequente formação de um novo lar. Uma explicação clássica para a diminuição da importância do casamento pode ser encontrada em $A$ treatise on the family, de Becker (1991), que abriu muitas portas para o estudo da família. $O$ autor argumenta que, no modelo tradicional em que o homem atua como provedor enquanto a mulher cuida da casa, os ganhos do casamento são ampliados em função da especialização dos papéis de gêneros. Com os movimentos femininos para empoderamento e melhoria no status das mulheres, as desigualdades entre os sexos no mercado de trabalho têm diminuído. Além disso, a necessidade de dupla renda para a sobrevivência de muitas 
famílias acabou por inserir as mulheres no mercado de trabalho. Assim, as funções de homens e mulheres na esfera da produção tornam-se mais similares, ${ }^{1}$ reduzindo supostos ganhos anteriormente associados à divisão sexual do trabalho entre o casal.

Com o adiamento da formação de união estável e aumento da idade no primeiro casamento (SURKYN; LESTHAEGHE, 2004), os jovens têm permanecido mais tempo na condição de dependência em relação aos pais, conforme Carvalho (2009). Todavia, a autora argumenta que o adiamento do casamento não é o único fator a explicar o retardamento da saída de casa, haja vista que muitos jovens saem de casa para viver uma união informal, enquanto outros se casam e continuam morando na casa dos pais.

Além da formação de um novo lar, a transição do jovem para a vida adulta é particularmente marcada pela saída da escola e entrada no mercado de trabalho, sendo esse processo caracterizado por inúmeras interações e tensões existentes entre esses dois universos. Assim, entender como se formam os objetivos e oportunidades nessa transição, em particular com relação à educação formal e inserção no mercado de trabalho, é tema central no estudo sobre o jovem (GOLGHER, 2010).

Nesse sentido, o curso de vida do jovem está despadronizado, trajetórias individuais são heterogêneas e pessoas de diferentes grupos etários estão expostas às mesmas experiências, assim como experiências distintas podem ser vivenciadas por pessoas do mesmo grupo etário. Partindo dessa despadronização, o European Group for Integrated Social Research (Egris) cunhou o termo “jovens adultos”. Segundo Mello (2005), o Egris é um esforço conjunto de pesquisadores de uma série de países europeus no sentido de aprofundar a discussão destes jovens "que não podem mais ser considerados jovens, mas, ao mesmo tempo, ainda não atingiram o status social de adultos no sentido tradicional. [...] entende-se como ‘jovens adultos' aqueles com idade entre 15 e 35 anos” (MELLO, 2005, p. 42). 0 conceito do Egris atualizou a definição anterior da Assembleia Geral da ONU (1985) de que jovens são aqueles que têm entre 15 e 24 anos. 0 limite inferior é definido biologicamente, pois aos 15 anos já estão desenvolvidas as funções sexuais e reprodutivas que diferenciam o adolescente da criança. O limite superior, todavia, é subjetivo. À medida que os filhos prolongam o tempo de permanência na casa dos pais, o conceito de jovem vai sendo redefinido (CAMARANO et al., 2004).

Embora a Secretaria Nacional de Juventude defina como jovens aqueles que possuem entre 15 e 29 anos (Lei n. 11.129/2005, art. 11), o presente artigo utiliza a faixa etária de 15 a 34 anos, uma vez que o tempo de permanência na casa dos pais se ampliou consideravelmente entre 1970 e 2000. 0 limite superior é arbitrário, tendo-se escolhido 34 anos porque, nessa idade, a maioria das pessoas já saiu da casa de seus pais, saiu da escola e entrou no mercado de trabalho, conforme será mostrado na análise descritiva e também de acordo com a literatura recente (MELLO, 2005).

\footnotetext{
${ }^{1}$ Apesar da diminuição do hiato nas últimas décadas, não se pode falar em simetria, pois existem diferenças salariais entre homens e mulheres desempenhando a mesma função e, na esfera familiar, o ônus é sempre maior para elas do que para eles.
} 
Assim, define-se como foco deste trabalho o estudo dos jovens brasileiros, analisando separadamente homens e mulheres, em função de sua inserção diferenciada no mercado de trabalho (ARABSHEIBANI; CARNEIRO; HENLEY, 2003; LEME; WAJNMAN, 2000; MADALOZZO, 2010; SALARDI, 2014; WAJNMAN; RIOS-NETO, 2000) e porque as mulheres tendem a estudar mais (WHINTER; GOLGHER, 2010). Por fim, e conforme ressaltado na introdução, não são abordadas as transições associadas ao estado civil e à fecundidade. A discussão tornar-se-ia por demais extensa, sendo que mecanismos que relacionam o crescimento econômico com tais transições diferem entre si e seria necessário expandir o grupo etário estudado, aumentando a heterogeneidade dos indivíduos analisados.

\section{Família e arranjos domiciliares}

Esta seção discute brevemente os conceitos de família e arranjo domiciliar. Há diversas definições de família. Etimologicamente, a família é o conjunto dos famulus, isto é, a criadagem do senhor patriarcal (OLIVEIRA, 1981). Pensando no conceito de família com uma perspectiva histórica estendida, fica claro que, nas sociedades de valores patriarcais, não havia espaço para a juventude, pois o pai centralizava as decisões. Todavia, com a perda de espaço da família tradicional patriarcal para outros arranjos, como as uniões informais, separações, recasamentos e famílias unipessoais, abre-se um leque de possibilidades para esses jovens - entre elas, a permanência na casa dos pais por um período mais longo que o tradicional.

De acordo com Carvalho (2009), a definição mais comum de família é a biológica, ou seja, um grupo de pessoas ligadas por uma relação sanguínea. Todavia, utilizaremos a mesma definição da autora, oriunda da demografia, na qual família é definida como o conjunto das pessoas que residem em uma mesma unidade doméstica e possuem laços diretos de parentesco, sejam sanguíneos, de casamento ou adoção, o que permite superar as dificuldades empíricas implicadas pela conceituação mais ampla de família.

\section{Revisão bibliográfica sobre os fatores que afetam a permanência do jovem na casa dos pais}

A maioria dos modelos econômicos trata a corresidência como uma forma de transferência intergeracional, semelhante à assistência financeira. 0 arcabouço utilitarista está no bojo de parcela significativa desses modelos. Para incluir a utilidade na discussão, todavia, são necessárias hipóteses em relação à preferência dos pais e filhos, isto é, qual a motivação por trás desse fluxo de recursos. Mais especificamente, prevalece o altruísmo ou é a vida um cálculo utilitarista? (AASVE et al., 2000). Geralmente os modelos assumem que os pais desejam a companhia dos filhos, mas os filhos têm demanda por privacidade (COBB-CLARK, 2008). Moretti (2005) ensina, todavia, que, enquanto em alguns países 
os pais preferem coabitar com os filhos, em outros os pais desejam que estes se tornem independentes o quanto antes.

A produção acadêmica sobre o prolongamento da juventude é extensa, particularmente quanto à decisão dos filhos em sair da casa dos pais. Não obstante, a saída da escola e a entrada no mercado de trabalho também recebem atenção, principalmente na Europa, América do Norte e Oceania (BOURASSA et al., 1994; CARD; LEMIEUX, 1997; AASVE et al., 2000, 2001; BILLARI et al., 2001; MANACORDA; MORETTI, 2005; BLANC; WOLFF, 2006; FUSELL, 2006; GIULIANO, 2007; COBB-CLARK, 2008). Alguns autores também discutiram o tema para a América do Sul (DE VOS, 1989; CAMARANO et al., 2004; MELLO, 2005; NASCIMENTO, 2006; VIEIRA, 2008; CARVALHO, 2009).

Aassve et al. (2001), em estudo com países europeus, analisaram como a decisão dos jovens em sair de casa é afetada pelo nível de emprego, salário dos jovens, renda dos pais e outros benefícios cedidos pelo Estado. Os autores argumentam que a disponibilidade de emprego geralmente é um fator de grande importância na decisão do jovem de sair de casa. Todavia, em países de orientação social democrata, os jovens recebem mais apoio do Estado e sua decisão de sair de casa depende menos do grau de desenvolvimento do mercado de trabalho. Em países como Itália e Espanha, onde o jovem tem pouco apoio do Estado, a oferta de empregos se mostrou mais importante na decisão de sair de casa. No começo dos anos 1990, 32\% dos jovens italianos e 25\% dos espanhóis ainda moravam com os pais aos 30 anos. Por outro lado, na Suécia, apenas $2 \%$ dos jovens se encontravam na mesma situação, frente a $5 \%$ na Holanda e $9 \%$ na França.

Blanc e Wolff (2006) analisaram a influência da renda de pais e filhos na probabilidade de estes saírem de casa, também para países europeus. Para alcançar tal objetivo, não se pode comparar a renda de filhos que coabitam com pais e a renda daqueles que deixaram 0 lar, pois esse procedimento implica endogeneidade e autosseleção. Os autores resolveram este problema por meio da utilização de um painel de indivíduos e acompanhamento de suas ações ao longo do tempo, preservando, assim, as informações sobre o background familiar daquele indivíduo que já saiu de casa. Os autores verificaram que a decisão de deixar a casa dos pais era positivamente relacionada com a renda do jovem. 0 efeito da renda dos pais foi de menor magnitude.

Em um estudo sobre a permanência de jovens italianos do sexo masculino na casa dos pais, Manacorda e Moretti (2005) utilizaram um choque exógeno do salário causado pelo aumento do tempo de aposentadoria ocasionado pela reforma da previdência italiana de 1992. Os autores verificaram uma relação positiva entre a renda dos pais e a permanência dos filhos na casa desses.

De acordo com Bourassa et al. (1994), o salário potencial que o jovem espera receber influi mais do que o salário disponível para a saída do jovem da casa dos pais. Afinal, o jovem pode financiar seu imóvel caso tenha uma expectativa otimista em relação ao mercado de trabalho. Os autores verificaram que o aumento do custo de moradia devido à diminuição de subsídios reduziu a taxa de jovens australianos entre os proprietários de imóveis. 
Card e Lemieux (1997) estudaram a influência das mudanças nas condições do mercado de trabalho e no salário dos jovens nos EUA e no Canadá sobre a probabilidade destes de continuar morando com os pais. Quando os babies do baby boom chegaram à idade de trabalhar, por volta de 1970, dada a coorte mais numerosa, houve uma maior competição por postos de trabalho, o que provocou o aumento de sua permanência na casa dos progenitores.

Diferentemente, um interessante estudo que capta a importância da "identidade cultural" foi realizado por Giuliano (2007). Para tanto, a autora estudou o comportamento de jovens americanos filhos de imigrantes, identificando semelhanças na maneira como esses compunham seu arranjo domiciliar e aqueles de idade semelhante que residiam no país de origem de seus pais. Este resultado ressalta a importância de características culturais relativamente às condições econômicas para explicar as diferenças observadas entre o comportamento de jovens de países distintos.

Camarano et al. (2004) encontraram um resultado semelhante analisando o cenário brasileiro nas últimas décadas. Dada a dificuldade crescente do jovem brasileiro em conquistar as condições materiais necessárias para sua autonomia, ele permanecia mais tempo na casa de seus pais. Similarmente, Mello (2005), estudando os jovens da região metropolitana do Rio de Janeiro, relata que a decisão de permanecer mais tempo na casa dos pais tinha como um dos pilares as crescentes dificuldades de inserção no trabalho, devido à maior competição dessa coorte no mercado de trabalho.

De forma diversa, Carvalho (2009) verificou que o ponto mais importante para a decisão do jovem em sair de casa era o fato de ter ou não mãe viva, indicando que os confortos do lar consistem em grandes atrativos para os jovens. Na mesma esteira, Camarano et al. (2004) alertam para uma possível dependência emocional dos filhos em relação aos pais. Nesse sentido, a extensão da juventude estaria associada à busca de suporte afetivo.

De toda sorte, com base nesta discussão, as evidências empíricas são inconclusivas no que diz respeito à importância relativa dos diversos fatores institucionais, macroeconômicos e culturais para explicar as grandes diferenças que jovens de países distintos apresentam para a formação do próprio lar (ver também COBB-CLARK, 2008). Além disso, deve-se ressaltar que existem fatores que sugerem a padronização das trajetórias dos jovens, como a modernização da sociedade, que promovem uma compactação das idades de formação do próprio lar, de evasão do sistema de ensino e do começo da participação no mercado de trabalho. Por outro lado, as transições mencionadas podem ser vistas menos como um conjunto discreto de experiências temporalmente marcadas, e mais como parte integral da biografia do indivíduo, refletindo decisões, oportunidades e limitações vividas pelo jovem. Assim, se com o advento da modernidade os indivíduos são menos restringidos por fatores tradicionalmente ligados à família e à origem socioespacial, eles terão maior poder decisório sobre a própria vida. Dessa forma, a ordem temporal dos marcadores da transição para a fase adulta, e em particular os três analisados nesse artigo, torna-se mais heterogênea (SHANAHAN, 2000). Ou seja, uma "padronização despadronizada". 
Uma metodologia distinta de todas as que foram apresentadas nestes trabalhos citados, e que pode acrescentar uma nova perspectiva para a discussão, em especial com relação a essa padronização, é a adotada por Fussell (2006) e Vieira (2008): a análise de entropia. Essa técnica permite visualizar quando começam e terminam os marcadores da transição para a vida adulta, bem como quando atingem o pico, em uma perspectiva distinta e direta. 0 trabalho de Fussell (2006) se distingue dos demais não apenas na metodologia, mas também por adotar um horizonte temporal muito mais extenso do que o restante da literatura, de 1800 a 2000, dando conta do movimento de marchas e contramarchas do prolongamento da juventude. Vieira (2008) analisa as trajetórias dos jovens brasileiros entre 1970 e 2000. Esse estudo serviu de inspiração para o presente trabalho e é a única pesquisadora brasileira a utilizar a metodologia de Theil/Fussell. Suas conclusões apontam na mesma direção da literatura mundial: entre 1970 e 2000 houve prolongamento da juventude.

0 presente trabalho, não obstante pautado na metodologia supracitada, parte de uma hipótese distinta: aliado a outros fatores, o bom crescimento econômico no período 2003-2011 pode ter interrompido esse fenômeno observado no Brasil nas últimas décadas. Além disso, do ponto de vista metodológico, este trabalho avança por construir intervalos de confiança para os índices de entropia por meio da técnica de booststrap, permitindo, portanto, inferir se as diferenças são significativas.

\section{Dados e métodos}

Para as análises descritiva e de entropia, apresentadas na próxima seção, foram utilizados os microdados da Pesquisa Nacional por Amostra de Domicílios (PNAD), realizada pelo Instituto Brasileiro de Geografia e Estatística (IBGE), de 2003 e 2011.

0 objeto desse estudo são os jovens de todas as regiões metropolitanas brasileiras, de ambos os sexos, com idade entre 15 e 34 anos, em 2003 e 2011. Optou-se pela exclusão de regiões não metropolitanas por duas razões: para homegeneizar a população de estudo; e porque a ampliação dos postos de trabalho, que se espera impactar a saída da casa dos pais, concentra-se em regiões metropolitanas.

Quanto à homogeneidade da população, jovens de regiões não metropolitanas podem apresentar realidades de vida muito distintas, tanto entre si quanto se comparados a jovens metropolitanos. Entre os primeiros, há aqueles que vivem no meio rural, em vilas e cidades de pequeno porte, bem como em centros urbanos maiores, os quais diferem amplamente. Já no caso metropolitano, não só são os jovens do meio rural minoria, mas as próprias zonas rurais tendem a ser fortemente ligadas às demais áreas metropolitanas. Isso se estabelece por meio de grandes fluxos de pessoas, serviços, bens e ideias, migração intrametropolitana e comutação - conjuntamente representados pelo conceito de urbanização extensiva (BETARELLI JR., 2014).

Adicionalmente, jovens metropolitanos têm um amplo mercado de trabalho local, bem como melhores opções de estudos, principalmente em nível superior. Nesse sentido, para os 
jovens de regiões não metropolitanas, o impacto da maior oferta de empregos sob a saída da casa dos pais tende a ser consideravelmente menor, uma vez que para eles a decisão de entrar no mercado de trabalho muitas vezes implica mudar de cidade e tem, assim, custos adicionais. Dessa forma, optou-se por considerar apenas os jovens metropolitanos. ${ }^{2}$

Embora haja uma série de variáveis que se relacionam à formação de lar próprio entre os jovens, discutidas anteriormente, o objetivo do presente artigo não é mensurar a influência dessas diversas variáveis sob a decisão dos jovens de continuar ou não na casa dos pais. Com efeito, o índice de entropia descrito a seguir mede quão heterogêneo é um sistema. Não se trata de estabelecer ou pressupor relações causais, sendo que as variáveis escolhidas (as três transições estudadas) são suficientes para o objetivo proposto de investigar se, paralelamente ao crescimento registrado no período de 2003 a 2011, há, entre os jovens, diminuição da frequência escolar acompanhada de aumento da participação na força de trabalho e saída da casa dos pais.

A análise de entropia é um conceito oriundo da termodinâmica e foi utilizada pela primeira vez nas ciências sociais em 1972, com a criação do índice de Theil (VIEIRA, 2008).

Do ponto de vista matemático o índice de Theil é bastante semelhante ao índice de entropia empregado por físicos e químicos. A interpretação deste índice, porém, é ligeiramente distinta dependendo do objeto de pesquisa: enquanto nas ciências naturais a entropia é uma medida de desordem do sistema, nas ciências sociais ela indica a transformação do sistema (VIEIRA, 2008).

O índice de entropia geral de Theil (1972), adaptado por Fussell (2006, p. 9), ${ }^{3}$ é dado por:

$$
E=\sum_{s=1}^{s} \rho(s, x) \times \operatorname{Ln}[1 / \rho(s, x)]
$$

Onde: $s$ representa determinada combinação de status; $x$ corresponde à idade; e $\rho(s, x)$ é a proporção da população na idade $x$ que pertence ao status $s$.

0 status do jovem pode ser o de responsável pelo domicilio ou filho, sendo que cada uma dessas possibilidades se desdobra em quatro combinações: estuda e trabalha; estuda e não trabalha; não estuda e trabalha; e não estuda e não trabalha. Portanto, há oito combinações distintas de status, o qual assume os valores $1 \leq s \leq 8$.

A idade assume valores entre $15 \leq x \leq 34$, uma vez que nos interessam os jovens de 15 a 34 anos.

$0 \leq \rho(s, x) \leq 1$, em que $\rho(s, x)=1$, indica que todos os jovens da idade se encontram no mesmo status e, nesse caso, a entropia será zero, situação de completa homogeneidade.

\footnotetext{
${ }^{2}$ Gostaríamos de agradecer a um parecerista anônimo por notar que, em função de nosso recorte geográfico, nossos resultados não são estritamente comparáveis àqueles discutidos na revisão de literatura. Afim de aumentar a robustez do estudo, repetimos o procedimento utilizando outros recortes (com e sem meio rural ou região metropolitana) e os resultados suportam nossas conclusões. Isto é, embora diferentes recortes geográficos tenham modificado a amplitude do fenômeno discutido, do ponto de vista qualitativo os resultados são semelhantes.

${ }^{3}$ A diferença do índice de Fussell é utilizar logaritmo natural, ao passo que Theil utiliza logaritmo (THEIL, 1972, p.21).
} 
A amplitude do índice de entropia geral varia de zero, perfeita homogeneidade, até a entropia máxima, situação em que há exatamente o mesmo número de indivíduos em cada uma das combinações de status. Ou seja, segundo Fussell (2006, p. 10), a entropia será máxima quando:

$\rho(s, x)=(1 / S), s=1,2, \ldots S$

O valor numérico que a entropia máxima assume depende de quantas combinações de status sejam incluídas no modelo (FUSSELL, 2006, p.10):

Entropia máxima $=\sum_{S=1}^{S}(1 / S) \times \operatorname{Ln}(S), \log 0:$

Entropia máxima $=\operatorname{Ln}(S)$

Portanto, a entropia de um sistema varia entre zero e $\operatorname{Ln}(S)$, em que $S$ é o número de combinações de status. Por fim define-se $\operatorname{Ln}(S)=100 \%$, de forma que o eixo das ordenadas varie entre $0 \%$ e $100 \%$ :

$E=\frac{\sum_{s=1}^{S} \rho(s, x) \times \operatorname{Ln}[1 / \rho(s, x)]}{\operatorname{Ln}(S)}$.

Em relação à estimativa do intervalo de confiança do índice de entropia, foram empregados procedimentos de reamostragem, uma vez que não se conhece a distribuição do índice de entropia, a partir do que seria possível calcular sua variância e testar, de maneira paramétrica, a hipótese de os desvios serem ou não estatisticamente significativos. Uma forma de contornar essa questão é oferecida pelo método de bootstrapping, que simula uma distribuição empírica do parâmetro em questão. 0 procedimento consiste em gerar $k$ novas amostras de $N$ observações a partir dos dados existentes, por meio de amostragem com reposição - onde $k$ é o número de repetições do procedimento e $N$ corresponde ao número de observações - e calcular o parâmetro de interesse para cada nova amostra. Se as observações da amostra original forem independentes e identicamente distribuídas, pode-se interpretar as $k$ estatísticas calculadas como representativas da distribuição do parâmetro estudado. A partir disso, é possível estimar intervalos de confiança e fazer testes de hipótese. No caso em questão, foram feitas 10.000 replicações e observados os percentis 5 e 95 do índice de entropia para cada idade e sexo.

\section{Análise descritiva: proporção de jovens que moram com os pais, estudam e trabalham}

Inicialmente, apresentamos a proporção de homens e mulheres que moram com os pais para os anos de 2003 e 2011. Conforme discutido na revisão da literatura, desde a década de 1970, em boa parte do mundo vem sendo documentado o prolongamento do tempo de permanência na casa dos pais de maneira sistemática. Se o crescimento econômico entre 2003 e 2011 tiver sido um contrapeso importante a esse fenômeno, não haverá mudanças significativas nesse período, ou será observada uma reversão dessa tendência. 
Com efeito, como mostra o Gráfico 1, tanto homens quanto mulheres alteraram pouco sua decisão em formar domicílio próprio. No caso feminino, praticamente não houve mudança ao longo do período analisado, enquanto para homens acima de 25 anos o retardamento da saída da casa dos pais é mais significativo. Portanto, no que tange à formação de domicílio próprio, o crescimento econômico não parece ter sido forte o suficiente para inverter o fenômeno, uma vez que existem inúmeros fatores que impactam a decisão do jovem em formar domicílio próprio, como discutido na revisão bibliográfica. Não obstante, entendemos que houve uma interrupção desse fenômeno, pois o aumento da proporção de jovens morando com os pais foi identificado apenas para homens com mais de 25 anos, sendo pouco significativo em comparação à intensidade do fenômeno nas décadas anteriores. Nascimento (2006), por exemplo, constatou crescimento significativo do percentual de jovens brasileiros de ambos os sexos morando com os pais entre 1970 e 2000, década após década, para todas as idades.

\section{GRÁFICO 1}

Proporção dos jovens morando na casa dos pais, por sexo, segundo idade Regiões metropolitanas do Brasil - 2003-2011

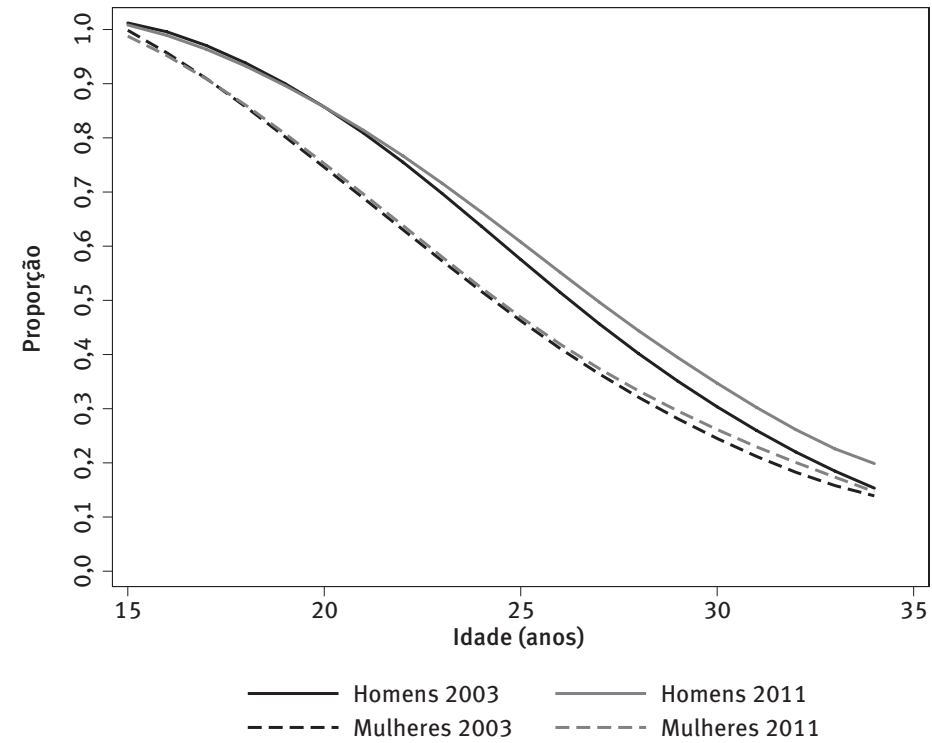

Fonte. IBGE. Pesquisa Nacional por Amostra de Domicílios - PNAD 2003 e 2011.

Na revisão da literatura, constatou-se que, entre 1970 e 2000, a ampliação do tempo de permanência na casa dos pais foi acompanhada pelo aumento da frequência escolar (CAMARANO et al., 2004; MELLO, 2005; NASCIMENTO, 2006; VIEIRA, 2008; CARVALHO, 2009). De 2003 a 2011 essa tendência se inverteu. Como se pode apreender do Gráfico 2, durante esse período a frequência à escola diminuiu para ambos os sexos em todas as idades.

Nossa interpretação para esse resultado é que, durante o período analisado, o mercado de trabalho ganhou importância relativamente à escola para os jovens, os quais parecem 
ter alterado um comportamento que havia se tornado estilizado: diante da competitividade crescente dessa coorte por emprego e crescimento modesto da economia, os jovens vinham prolongando a permanência na casa de seus pais e aumentando a frequência escolar. $A$ partir de 2000, com o expressivo crescimento da economia, eles começaram a se afastar dos paradigmas de "geração canguru" - jovens que têm permanecido cada vez mais tempo na casa dos pais - e "geração bumerangue" - aqueles que saem e retornam para a casa dos pais (NASCIMENTO, 2006).

É importante ressaltar dois fatores associados ao sistema de ensino brasileiro que podem estar impactando este resultado. Houve significativa correção dos fluxos escolares no Brasil. Assim, muitos jovens que estariam frequentando o ensino fundamental ou o ensino médio com elevada distorção idade-serie, caso não tivessem concluído o nível desejado, evadiram do sistema de ensino após concluir determinado nível, em especial na conclusão do ensino médio (GOLGHER, 2010). Além disso, as taxas de evasão no ensino médio são hoje bastante elevadas, em especial de jovens do sexo masculino (CAMARANO; KANSO, 2008; INEP, 2008).

GRÁFICO 2

Proporção dos jovens frequentando a escola, por sexo, segundo idade

Regiões metropolitanas do Brasil - 2003-2011

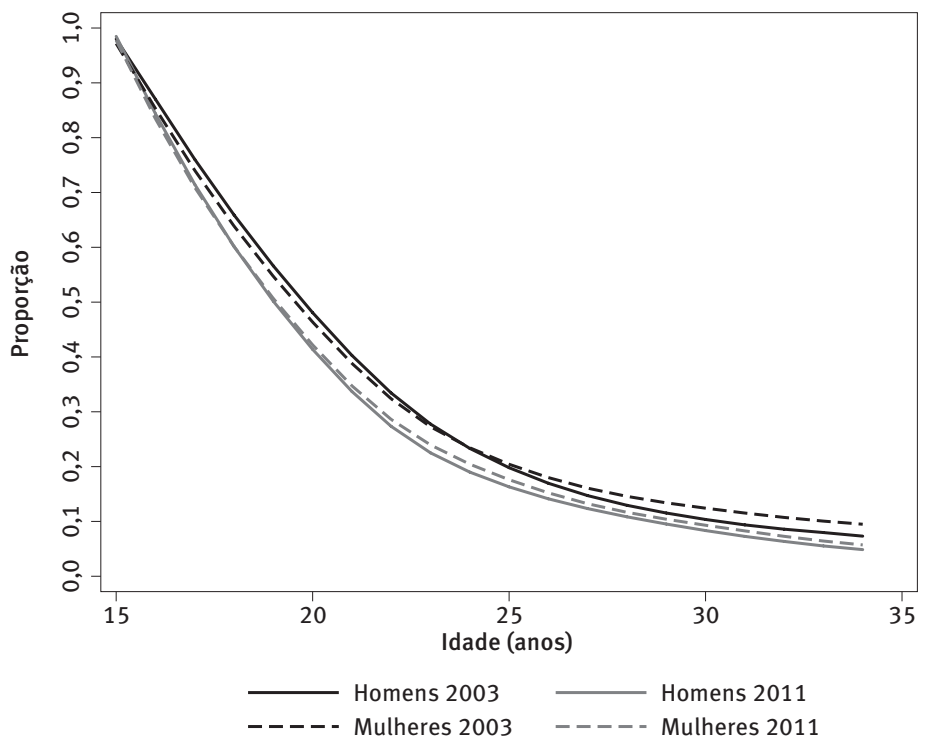

Fonte. IBGE. Pesquisa Nacional por Amostra de Domicílios - PNAD 2003 e 2011.

Os resultados discutidos causam certa inquietação. Partindo do pressuposto de que a maioria dos jovens tem preferências hiperbólicas (OREOPOULOS, 2007), eles valorizam o consumo presente substancialmente mais do que o futuro, uma vez que a utilidade futura é descontada a uma taxa alta (LEVITT et al., 2012). O corolário é que existe pouco investimento em educação. Assim, há um esforço mundial no sentido de diminuir as taxas de 
evasão escolar e diversas políticas públicas que visam incentivar o aluno a permanecer na escola por mais tempo (DEARDEN et al., 2005).

Para finalizar a seção, apresenta-se a proporção de jovens trabalhando por idade. Conforme argumentamos na revisão da literatura, há uma série de fatores que influenciam a decisão do jovem de sair de casa, sendo a participação no mercado de trabalho uma das mais relevantes. 0 Gráfico 3 explora essa última dimensão e revela que a proporção de jovens trabalhando aumentou consideravelmente no período.

\section{GRÁFICO 3}

Proporção dos jovens trabalhando, por sexo, segundo idade Regiões metropolitanas do Brasil - 2003-2011

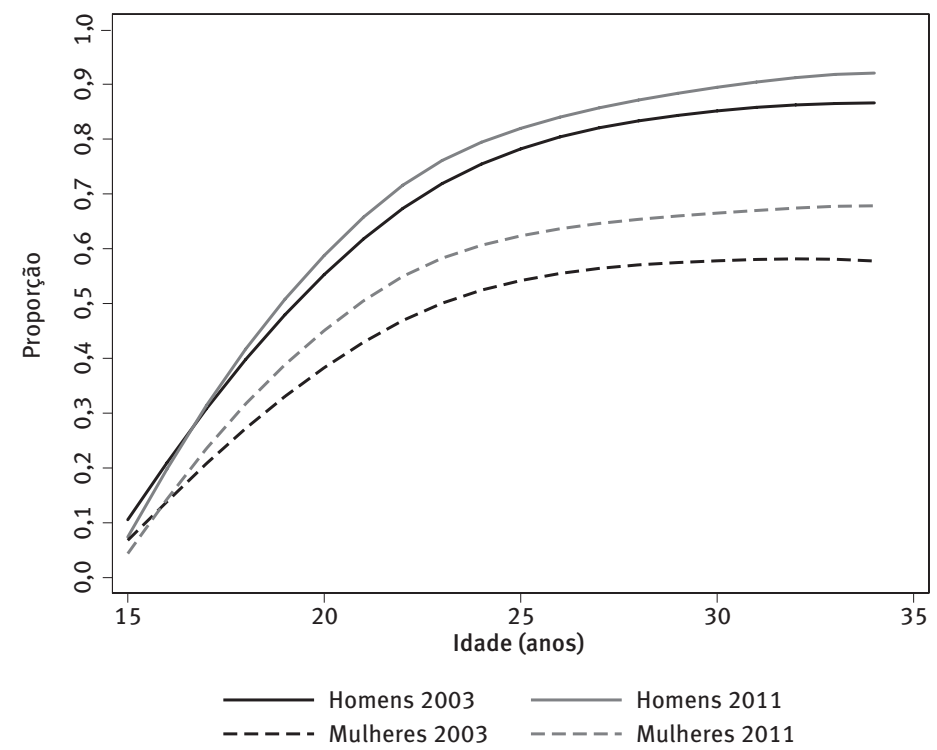

Fonte. IBGE. Pesquisa Nacional por Amostra de Domicílios - PNAD 2003 e 2011.

Analisando conjuntamente os três gráficos, parece haver subsídio para a hipótese de que, entre 2003 e 2011, houve uma reversão do comportamento dos jovens. Enquanto a proporção de jovens morando com os pais praticamente não se alterou no período estudado, a daqueles que frequentam a escola diminuiu, ao passo que a proporção de jovens que trabalham aumentou.

A razão para dividir a análise por sexo, procedimento padrão na literatura que trata as transições para a vida adulta (como a decisão de formar domicílio próprio e a entrada no mercado de trabalho), fica clara quando comparamos o comportamento de homens e mulheres nos três gráficos anteriores. Em primeiro lugar, para todas as idades, há uma porcentagem menor de mulheres morando na casa dos pais comparativamente aos homens. Ademais, para ambos os sexos, é possível perceber que o hiato entre 2003 e 2011 é maior entre os homens do que entre as mulheres. Ou seja, as melhores condições econômicas, 
aliadas ao aumento relativo da escolaridade da mulher e da participação feminina no mercado de trabalho, como descrito posteriormente, parecem ter sido um estímulo maior para as mulheres do que para os homens na hora de decidir entre sair ou não da casa dos pais.

Isso provavelmente reflete o fato de que residir com os pais representa um custo maior para as mulheres do que para os homens. Talvez os pais sejam mais rígidos com as filhas em comparação aos filhos, em função de vivermos em uma sociedade que segue com diversas dimensões patriarcais. Somando-se a isso o movimento histórico feminista de busca por igualdade entre os gêneros, é natural que o comportamento de homens e mulheres seja tão distinto, seus objetivos e estímulos são outros. Conquistar a independência parece ser mais atrativo para mulheres do que para homens, seja pelo fato de que os custos de ficar em casa são mais altos para elas, seja porque, para a mulher, a independência significa, além de sair da casa dos pais, autoafirmação da capacidade feminina em um mundo machista.

Comparando a decisão de estudar e trabalhar, nota-se que a frequência escolar diminuiu mais entre homens do que entre mulheres, enquanto a proporção de jovens trabalhando aumentou mais para as mulheres do que para os homens. Para idades acima de 18 anos, as mulheres apresentam maior frequência escolar do que os homens e estão fechando o hiato em relação a eles no que tange ao trabalho.

No Gráfico 2 nota-se que, em 2003, os homens de 15 a 24 anos apresentavam maior frequência escolar do que as mulheres. Em 2011, todavia, apenas homens entre 15 e 18 anos registravam maior frequência escolar do que as mulheres. Além disso, a distorção idade-série de homens tende a ser maior, ou seja, eles frequentam níveis escolares mais baixos para idades semelhantes (GOLGHER, 2010).

O Gráfico 3 mostra que, para todas as idades, há uma maior proporção de homens trabalhando do que mulheres. Não obstante, é também nítido que o hiato diminuiu consideravelmente para um período tão curto, ou seja, a proporção de jovens que trabalham cresceu muito mais entre as mulheres. A redução desse hiato é também verificada com relação aos rendimentos do trabalho (HAUSSMANN; GOLGHER, 2014).

Essa seção apresentou algumas tendências gerais das transições do jovem quanto ao local de moradia, inserção no sistema de educação formal e no mercado de trabalho. A seguir, essas tendências são exploradas em conjunto com o uso da análise de entropia.

\section{Análise de entropia}

A análise de entropia é uma alternativa à ausência de dados em painel. Como não podemos acompanhar os indivíduos ao longo do tempo para examinar algumas das transições para a vida adulta, optamos por esse método que possui grande poder analítico. A análise de entropia estima o grau de heterogeneidade de um sistema, sendo que nesse trabalho examinamos a relação entre frequentar escola, trabalhar e formação de domicílio próprio. 0 objetivo não é determinar relações de causalidade entre as variáveis, mas sim verificar a heterogeneidade dos caminhos percorridos pelos jovens. 
Foram construídos índices de entropia para 2003 e 2011, divididos por sexo, a fim de analisar as três dimensões discutidas anteriormente em conjunto. Os resultados apresentaram a mesma tendência geral para ambos os sexos.

Tanto Fussell (2006) quanto Vieira (2008), respectivamente para jovens americanos e brasileiros, calculando a entropia entre 1970 e 2000, encontraram resultados similares. 0 índice de entropia aumentou década após década e o máximo do gráfico se moveu para idades mais avançadas ao longo do tempo. Como a entropia representa a heterogeneidade do sistema, maiores valores implicam que os jovens estão demorando mais tempo para realizar as transições descritas anteriormente, permanecendo em diferentes combinações de status por períodos mais extensos, resultado que vai ao encontro do que foi discutido pela literatura ao longo das últimas décadas.

Quando calculamos a entropia para o Brasil em 2003 e 2011, todavia, em um outro contexto econômico, os resultados indicam o novo comportamento discutido na seção anterior. 0 índice de entropia, para ambos os sexos, é inferior em 2011 comparativamente a 2003 para a maioria dos grupos etários analisados em ambos os sexos, como mostram os Gráficos 4 e 5, respectivamente, para homens e mulheres. Nota-se que as diferenças são estatisticamente significantes, dado que os valores de 2003 não estão compreendidos no intervalo de confiança para 2011, evidenciando que os resultados encontrados são robustos. Para homens e mulheres, a entropia em 2011 é superior à de 2003 apenas entre 16 e 18 anos, indicando que os jovens entraram no mercado de trabalho mais cedo, adicionando heterogeneidade ao sistema, o que também ocorre para mulheres com 19 anos. Contudo, a partir dos 20 anos, o índice é sempre inferior em 2011, implicando que o sistema tornou-se mais homogêneo e os jovens completaram as transições mais rapidamente em idades similares.

É importante observar que a menor entropia não significa que o jovem tenha saído mais cedo de casa; como vimos, a proporção de jovens morando com os pais teve um pequeno aumento para homens acima de 25 anos e não se alterou significativamente para mulheres. $A$ transição para a vida adulta contempla, entretanto, não apenas sair de casa, mas também sair da escola e entrar no mercado de trabalho, entre outras transições. E, como foi visto, há menor proporção de jovens estudando e maior proporção trabalhando. A menor entropia em 2011 indica maior homogeneidade nas trajetórias dos jovens, ao contrário da despadronização do curso de vida discutida na revisão da literatura. Ou seja, verificamos certa repadronização nas trajetórias dos jovens com maior homogeneidade nas três transições discutidas.

A variação no índice de entropia para mulheres apresenta a mesma tendência dos homens. Além de registrar valores inferiores em 2011 relativamente a 2003, o valor máximo do índice em 2003 foi observado para jovens mulheres de 22 anos, enquanto em 2011 isso ocorreu para 21 anos. 0 pico do gráfico é importante, pois representa o momento de máxima heterogeneidade do grupo: à medida que se distancia do pico para a esquerda, aproxima-se da filha que mora com os pais, estuda e não trabalha, enquanto o mesmo movimento para a direita significa a aproximação da mulher responsável pelo lar, que não estuda e trabalha. 
GRÁFICO 4

Índice de entropia (e intervalos de confiança-IC) para homens jovens, por idade Regiões metropolitanas do Brasil - 2003-2011

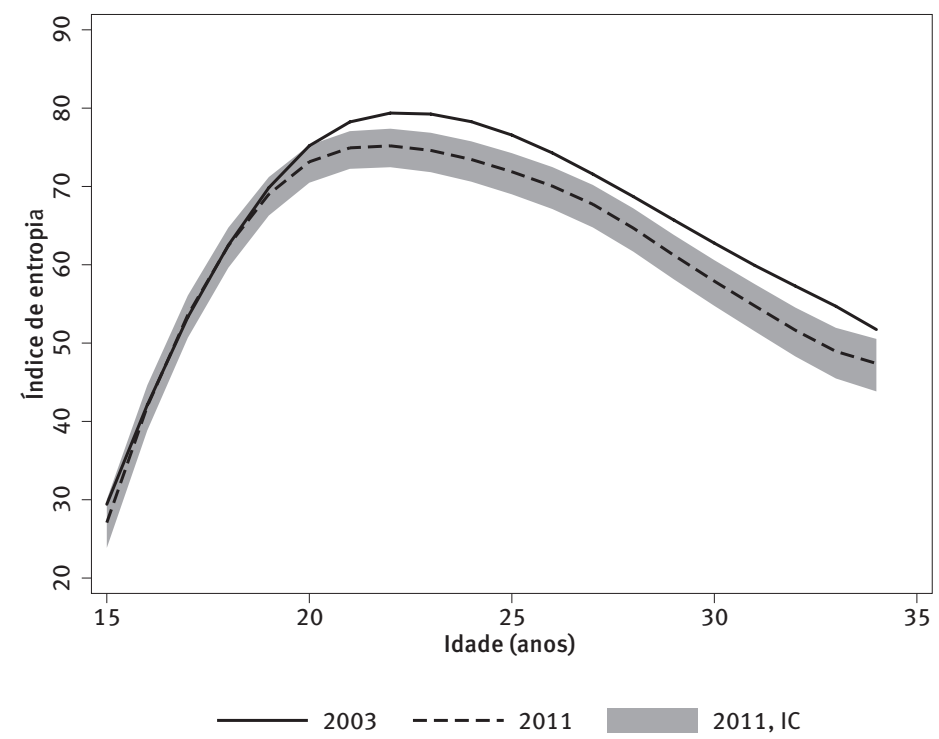

Fonte. IBGE. Pesquisa Nacional por Amostra de Domicílios - PNAD 2003 e 2011.

\section{GRÁFICO 5}

Índice de entropia (e intervalos de confiança-IC) para mulheres jovens, por idade Regiões metropolitanas do Brasil - 2003-2011

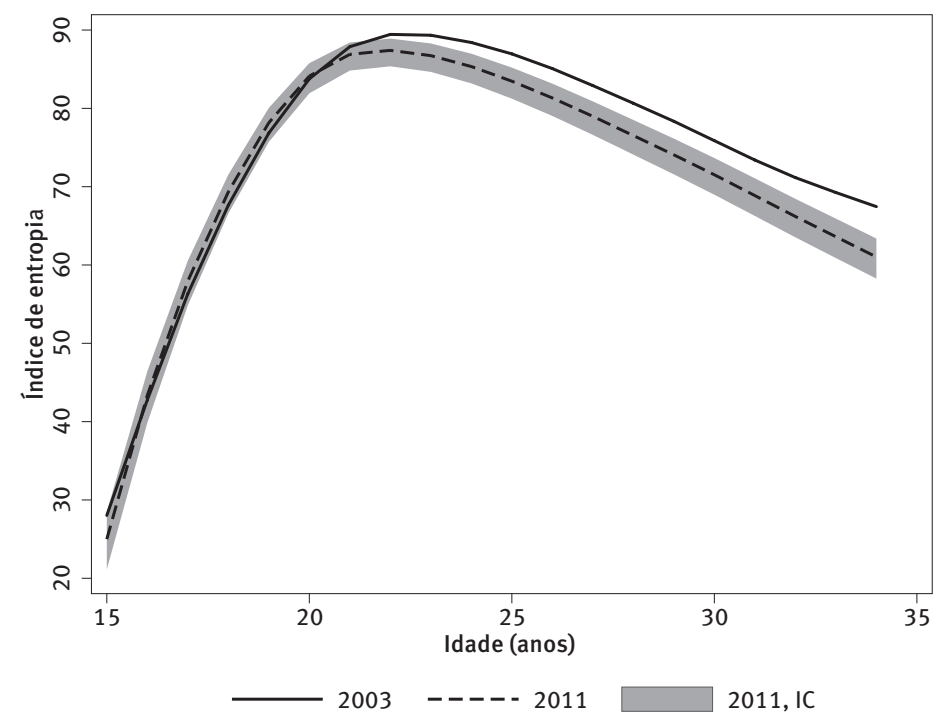

Fonte. IBGE. Pesquisa Nacional por Amostra de Domicílios - PNAD 2003 e 2011. 


\section{Considerações finais}

O prolongamento da juventude é um fenômeno mundial amplamente discutido desde a década de 1970. A literatura que trata o assunto é muito mais extensa na Europa e nos Estados Unidos em comparação ao Brasil, o que é natural em qualquer assunto. Todavia, para além desse hiato que seria esperado, a produção acadêmica no Brasil é seriamente restringida pelo fato de não termos boas bases de dados em painel, em especial dados microlongitudinais. Não obstante seja possível analisar trajetórias com dados cross-section, por exemplo por meio do uso de pseudopainéis (DEATON, 1985), sem dúvida dados longitudinais ampliam as opções do pesquisador. Outra opção de técnica que trabalha efetivamente com dados cross-section é a analise de entropia aqui empreendida.

A análise descritiva para 2003 e 2011 mostrou que a proporção de jovens em regiões metropolitanas morando com os pais manteve-se estável para mulheres e elevou-se apenas para homens com mais de 25 anos, uma mudança no padrão de aumento significativo que vinha ocorrendo entre 1970 e 2000. Ademais, a proporção de jovens que estudam diminuiu, fato que contraria as tendências recentes, em parte devido ao ajustamento dos fluxos de estudantes e à diminuição da distorção idade-série. Finalmente, cresceu a proporção daqueles que trabalham, indicando um comportamento distinto do discutido na literatura.

Por fim, realizamos a análise de entropia objetivando compreender melhor o processo múltiplo de trajetórias de jovens e suas mudanças entre 2003 e 2011. Em primeiro lugar, a idade que corresponde ao máximo de entropia diminuiu para homens e mulheres. Ou seja, o momento de máxima heterogeneidade na trajetória dos jovens de regiões metropolitanas passou a ocorrer em uma idade inferior. Mais significativo ainda é que o índice de entropia assume valores menores em 2011 para homens e mulheres acima de 20 anos, o que indica que os jovens aceleraram sua transição para a vida adulta, em parte como resposta às boas condições econômicas do período.

Apesar da dificuldade em se compreender o fenômeno da juventude, por sua complexidade e seu dinamismo, o sucesso da formulação de políticas públicas destinadas a esse grupo passa por tal entendimento. Mello (2005) argumenta que a maioria das políticas supostamente dirigidas aos jovens é, na verdade, destinada a um público mais amplo, sendo necessário competir por tais benefícios. 0 caso brasileiro é particularmente importante, uma vez que o país figura entre os lideres mundiais no prolongamento da juventude (CARVALHO, 2009).

Somente o tempo irá dizer se o período entre 2003 e 2011 foi realmente um divisor de águas ou apenas um interstício da tendência ao prolongamento da juventude. Afinal, nosso argumento foi de que o bom crescimento econômico interrompeu essa tendência. Todavia, em meio à crise mundial que se iniciou em 2007 e com a desaceleração do crescimento do PIB brasileiro, que se arrasta desde 2011 e não dá sinais de melhorias, é difícil saber se o fantasma dos filhos que nunca querem sair de casa voltará a assombrar os pais. Ou será que eles gostam? 


\section{Referências}

AASSVE, A.; BILLARI, F. C.; MAZZUCO, S.; ONGARO, F. Leaving home ain't easy: a comparative longitudinal analysis of ECHP data. Rostock: Max Planck Institute for Demographic Research, 2001 (Working paper, n. 38).

AASSVE, A.; BILLARI, F. C.; ONGARO, F. The impact of income and employment status on leaving home: evidence from the Italian ECHP sample. Rostock: Max Planck Institute for Demographic Research, 2000 (Working paper, n. 122).

ARABSHEIBANI, G.; CARNEIRO, F.; HENLEY, A. Gender wage differentials in Brazil: trends over a turbulent era. World Bank Policy Research, 2003 (Working paper, n. 3148).

BECKER, G. S. A treatise on the family. Cambridge, MA: Harvard University Press, 1981.

BETARELLI JUNIOR, A.; MONTE MÓR, R.; SIMÕES, R. Urbanização extensiva e o processo de interiorização do estado de São Paulo: um enforque contemporâneo. Revista Brasileira de Estudos Urbanos e Regionais, v. 15, n. 2, p. 179-197, 2014.

BILLARI, F. C.; PHILIPOV, D.; BAIZÁN, P. Leaving home in Europe: the experience of cohorts born around 1960. Rostock: Max Planck Institute for Demographic Research, 2001 (Working paper, n. 014).

BLANC, D.; WOLFF, F. C. Leaving home in Europe: the role of parents and children's incomes. Review of Economics of the Household, v. 4, n. 1, p. 53-73, 2006.

BLAU, F.; KAHN, L. Gender differences in pay. Cambridge, MA: National Bureau of Economic Research - NBER, 2000 (Working paper, n. 7732).

BOURASSA, S. C.; HAURIN, D. R.; HAURIN, R. J.; HENDERSHOTT, P. H. Independent living and home ownership: an analysis of Australian youth. Australian Economic Review, v. 27, n. 3, p. 29-44, 1994.

BROWN, C.; CORCORAN, M. Sex-based differences in school content and the male/female wage gap. Cambridge, MA: National Bureau of Economic Research - NBER, 1996 (Working paper, n. 5580).

BRUSCHINI, C. Trabalho doméstico: inatividade econômica ou trabalho não-remunerado? Revista Brasileira de Estudos de População, v. 23, n. 2, p. 331-353, 2006.

CAMARANO, A. A.; MELLO, J. L.; KANSO, S.; PASINATO, M. T. Caminhos para a vida adulta: as múltiplas trajetórias dos jovens brasileiros. Última Década, v. 12, n. 21, p.11-50, 2004.

CAMARANO, A. A.; KANSO, S. O que estão fazendo os jovens que não estudam, não trabalham e não procuram trabalho? Boletim Mercado de Trabalho - Conjuntura e Análise, Brasília, n. 53, p. 37-44, 2008.

CARD, D.; LEMIEUX, T. Adapting to circumstances: the evolution of work, school and living arrangements among North American youth. Cambridge, MA: The National Bureau of Economic Research - NBER, 1997 (Working paper, n. 6142).

CARVALHO, R. L. Casa, comida e roupa lavada: fatores associados à saída do jovem brasileiro do domicílio de origem. Dissertação (Mestrado) - Centro de Desenvolvimento e Planejamento Urbano - Cedeplar/Universidade Federal de Minas Gerais - UFMG, Belo Horizonte, 2009.

COBB-CLARK, D. A. Leaving home: what economics has to say about the living arrangements of young Australians. Bonn: Institute for the Study of Labor, 2008 (Discussion paper, n. 3309).

DAYRELL, J. 0 jovem como sujeito social. Revista Brasileira de Educação, n. 24, 2003.

DEARDEN, L.; EMMERSON, C.; FRAYNE, C.; MEGHIR, C. Education subsidies and school drop-out rates. Londres: Institute for Fiscal Studies, 2005 (Working paper, n. 05/11).

DEATON, A. Panel data from time series of cross-sections. Journal of Econometrics, Amsterdam, v. 30, n. 1, p. 109-126, 1985. 
DE VOS, S. Leaving the parental home: patterns in six Latin American countries. Journal of Marriage and the Family, v. 51, n. 3, p. 615-626, 1989.

FUSSELL, E. Structuring the transition to adulthood: an entropy analysis of the early life course in the United States, 1880 to 2000. In: POPULATION ASSOCIATION OFAMERICA MEETING. Los Angeles, 2006. Disponivel em: 〈http://paa2006.princeton.edu/papers/60160〉. Acesso em: 22 mar. 2016.

GIULIANO, P. Living arrangements in Western Europe: does cultural origin matter? Journal of the European Economic Association, v. 5, n. 5, p. 927-952, 2007.

GOLGHER, A. Diálogos com o ensino médio 2: o ensino médio no Brasil visto a partir do modelo profluxo e outros indicadores demográficos. Belo Horizonte: Centro de Desenvolvimento e Planejamento Urbano Cedeplar/Universidade Federal de Minas Gerais - UFMG, 2010 (Texto para discussão, n. 392).

HAUSSMANN, S.; GOLGHER, A. The end of male dominance? An analysis of the Brazilian labor market using the APC approach. In: XIX ENCONTRO NACIONAL DE ESTUDOS POPULACIONAIS. Anais... Águas de São Pedro: Abep, 2014.

IBGE - Instituto Brasileiro de Geografia e Estatística. Pesquisa Nacional por Amostra de Domicílios (PNAD) 2003. Rio de Janeiro, 2004.

Pesquisa Nacional por Amostra de Domicílios (PNAD) 2011. Rio de Janeiro, 2012.

INEP - Instituto Nacional de Estudos e Pesquisas Educacionais Anísio Teixeira. Sinopse Estatística da Educação Básica 2007. Brasília, 2008. Disponível em: 〈http://portal.inep.gov.br/basicacenso-escolar-sinopse-sinopsè.

Sinopse Estatística da Educação Básica 2008. Brasília, 2009. Disponível em: 〈http:// portal.inep.gov.br/basica-censo-escolar-sinopse-sinopse〉.

JUHN, C.; POTTER, S. Changes in labor force participation in the United States, Journal of Economic Perspectives, v. 20, n. 3, p. 27-46, 2006.

LEME, M.; WAJNMAN, S. Tendências de coorte nos diferenciais de rendimentos por sexo. In: HENRIQUES, R. (Org.). Desigualdade e pobreza no Brasil. Rio de Janeiro: Ipea, 2000.

LEVITT, S.; LIST, J.; NECKERMANN, S.; SADOFF, S. The behavioralist goes to school: leveraging behavioral economics to improve educational performance. Cambridge, MA: The National Bureau of Economic Research - NBER, 2012 (Working paper, n. 18165).

MADALOZZO, R. Occupational segregation and the gender gap in Brazil: an empirical analysis. Economia Aplicada, v. 14, n. 2, p. 147-168, 2010.

MANACORDA, M.; MORETTI E. Why do most Italian young men live with their parents? Intergenerational transfers and household structure. Centre for Economic Policy Research, 2005 (Discussion paper, n. 5116).

MELLO, J. L. Transições para a vida adulta: os jovens da região metropolitana do Rio de Janeiro. Dissertação (Mestrado) - Escola Nacional de Ciências Estatísticas, Instituto Brasileiro de Geografia e Estatística, Rio de Janeiro, 2005.

NASCIMENTO, A. M. Transição para a vida adulta: situação dos filhos adultos brasileiros no período 1970-2000. Dissertação (Mestrado) - Escola Nacional de Ciências Estatísticas, Instituto Brasileiro de Geografia e Estatística, Rio de Janeiro, 2006.

NOPO, H. Promoting equality in the country with the largest earnings gaps in the region: Brazil 1996-2006. New century, old disparities: gender and ethnic earnings gaps in Latin America and the Caribbean. Washington, DC: Inter-American Development Bank and World Bank, 2012a.

ÑOPO, H. More schooling, lower earnings: women's earnings in Latina America and the Caribbean. New Century, old disparities: gender and ethnic earnings gaps in Latin America and the Caribbean. Washington, DC: Inter-American Development Bank and World Bank, 2012b. 
OLIVEIRA, J. C. A. Dos pictogramas à videologia. Análise e Conjuntura, v. 11, n. 7/8, p. 260-266, 1981. OREOPOULOS, P. Do dropouts drop out too soon? Wealth, health and happiness from compulsory schooling. Journal of Public Economics, v. 91, n. 11-12, p. 2213-2229, 2007.

POTTER, J.; SCHMERTMANN, C.; ASSUNÇÃO, R.; CAVENAGHI, S. Mapping the timing, pace, and scale of the fertility transition in Brazil. Population and Development Review, v. 36, n. 2, p. 283-307, 2010.

SALARDI, P. The evolution of gender and racial occupational segregation across formal and non-formal labor markets in Brazil, 1987 to 2006. Review of Income and Wealth, p. 1-22, 2014.

SHANAHAN, M. Pathways to adulthood in changing societies: variability and mechanisms in life course perspective. Annual Review of Sociology, n. 26, p. 667-692, 2000.

SURKYN, J.; LESTHAEGHE, R. Value orientations and the second demographic transition (SDT) in Northern, Western and Southern Europe: an update. Demographic Research, Special Collection 3, Article 3, 2004.

THEIL, H. Statistical decomposition analysis: with applications in the social and administrative sciences. Amsterdam: North-Holland Publishing Company, 1972.

VIEIRA, J. M. Transição para a vida adulta no Brasil: análise comparada entre 1970 e 2000. Revista Brasileira de Estudos de População, v. 25, n. 1, p. 27-48, 2008.

WEICHSELBAUMER, D.; WINTER-EBMER, R. A meta-analysis of the international gender wage gap. Linz, Áustria: Department of Economics, Johannes Kepler University of Linz, 2003 (Working paper, n. 0311).

WHINTER, J. M.; GOLGHER, A. Uma investigação sobre a aplicação de bônus adicional como política de ação afirmativa na Universidade Federal de Minas Gerais (UFMG). Revista Brasileira de Estudos de População, v. 27, n. 2, p. 333-360, 2010.

\section{Sobre os autores}

Thiago Dumont Oliveira é graduado em Ciências Econômicas pela Universidade Federal de Minas Gerais (UFMG) e mestrando em economia no Centro de Desenvolvimento e Planejamento Regional (Cedeplar/UFMG).

André Braz Golgher é graduado em Física pela Universidade Federal de Minas Gerais (UFMG), mestre em Química pela UFMG e doutor em Demografia pelo Centro de Desenvolvimento e Planejamento Regional (Cedeplar/UFMG). É professor adjunto do Cedeplar e Face da Universidade Federal de Minas Gerais.

Pedro Mendes Loureiro é graduado em Ciências Econômicas pela Universidade Federal de Minas Gerais (UFMG), mestre em economia pela Universidade Estadual de Campinas (Unicamp) e doutorando em Economia na Soas, University of London.

\section{Endereço para correspondência}

\section{Thiago Dumont Oliveira}

Rua Caldeira Brant, 41, ap. 305, Bairro Sagrada Família

31030-180 - Belo Horizonte-MG, Brasil

André Braz Golgher

Cedeplar, Universidade Federal de Minas Gerais

Av. Antônio Carlos, Bairro Pampulha

30000-000 - Belo Horizonte-MG 


\author{
Pedro Mendes Loureiro \\ 31 Hanover Road, N15 4DL \\ Londres, Reino Unido
}

\begin{abstract}
Young Brazilians' housing, education and work trajectories between 2003 and 2011: an entropy analysis
\end{abstract}

Academic evidence from all over the world, including Brazil, shows that young people have increasingly delayed the decision to leave their parents' home since the 1970s. This paper studies the decisions of young people regarding living with their parents, studying and working. Our goal is to evaluate how young people's transition to adulthood changed as a result of sustained economic growth between 2003 and 2011. Using the National Household Sample Surveys (PNADs) of 2003 and 2011, we calculate the proportion of people between 15 and 34 years in metropolitan areas living with parents, studying and working. The fraction of young people living with their parents did not change significantly between 2003 and 2011, but there was a drop in school attendance and the proportion of young people working increased. In order to assess the interplay of these three dimensions we performed an entropy analysis. Our results suggest a reversal of the pattern of extending youth which has been widely debated over the last decades.

Keywords: Entropy analysis. Household composition. Education. Labor market. Transition to adulthood.

\title{
Resumen
}

Trayectorias de vivienda, estudio y trabajo de los jóvenes brasileños entre 2003 y 2011: un análisis de entropía

En todo el mundo, Brasil incluso, varios estudios demuestran que el periodo en que los jóvenes permanecen en la casa de sus padres ha aumentado entre los años 1970 y 2000 . El objetivo de este trabajo es de evaluar como esta tendencia ha sido afectada por el crecimiento económico sostenido registrado en el periodo 2003 a 2011. Utilizando los microdatos de la PNAD (Encuesta Nacional de Hogares por Muestreo) de los años 2003 y 2011, se estima la proporción de jóvenes entre 15 y 34 años de edad en las áreas metropolitanas que viven con los padres, estudian o trabajan. La proporción de jóvenes que viven con sus padres no ha cambiado significativamente entre 2003 y 2011, pero hubo una disminución relativa de la asistencia a la escuela en esta cohorte y un aumento en la proporción de trabajadores entre los jóvenes. Luego se realizó un análisis de la entropía con el objetivo de investigar la interacción entre estas tres dimensiones. Los resultados sugieren una ruptura con el paradigma de la prolongación de la juventud que ha sido ampliamente discutido en las últimas décadas.

Palabras clave: Análisis de la entropía. Composición del hogar. Educación. Mercado de trabajo. Transición a la vida adulta.

Recebido para publicação em 12/10/2015

Recomendado para publicação em 21/03/2016

Aceito para publicação em 26/03/2016 